\title{
Acoustic Emission Signal Application on Damage Evaluation of RC Beam-Column Joint under Monotonic Loading
}

\author{
Md Nor N. ${ }^{1, *}$, Jalilluddin A. M. ${ }^{2}$, Mohamad M. Z. ${ }^{3,4}$, Mat Saliah S. N. ${ }^{1}$, Ibrahim A. ${ }^{4}$, Abd Ghani K. D. ${ }^{1}$ \\ ${ }^{1}$ School of Civil Engineering, College of Engineering, Universiti Teknologi MARA, Cawangan Pulau Pinang, Pulau Pinang, Malaysia \\ ${ }^{2}$ School of Civil Engineering, College of Engineering, Universiti Teknologi MARA, Cawangan Pahang, Malaysia \\ ${ }^{3}$ Annexe 2, Persada PLUS, Persimpangan Bertingkat Subang, Petaling Jaya, Selangor, Malaysia \\ ${ }^{4}$ School of Civil Engineering, College of Engineering, Universiti Teknologi MARA, Malaysia
}

Received January 29, 2021; Revised July 27, 2021; Accepted August 19, 2021

\section{Cite This Paper in the following Citation Styles}

(a): [1] Md Nor N., Jalilluddin A. M., Mohamad M. Z., Mat Saliah S. N., Ibrahim A., Abd Ghani K. D. , "Acoustic Emission Signal Application on Damage Evaluation of RC Beam-Column Joint under Monotonic Loading," Civil Engineering and Architecture, Vol. 9, No. 5A, pp. 121 - 127, 2021. DOI: 10.13189/cea.2021.091314.

(b): Md Nor N., Jalilluddin A. M., Mohamad M. Z., Mat Saliah S. N., Ibrahim A., Abd Ghani K. D. (2021). Acoustic Emission Signal Application on Damage Evaluation of RC Beam-Column Joint under Monotonic Loading. Civil Engineering and Architecture, 9(5A), 121 - 127. DOI: 10.13189/cea.2021.091314.

Copyright $\mathrm{C} 2021$ by authors, all rights reserved. Authors agree that this article remains permanently open access under the terms of the Creative Commons Attribution License 4.0 International License

\begin{abstract}
Beam-column joint in reinforced concrete (RC) structure is a critical element that needs to be monitored continuously throughout its service life. The beam-column connection acts as the core component that receives moment transfer from adjacent elements. Consequently, the integrity of the $\mathrm{RC}$ beam-column joint reduces when subjected to load over time. This study investigates the damage of $\mathrm{RC}$ beam-column joint subjected to static load until failure using acoustic emission (AE) signal strength. The size of the RC joint sample was composed of $300 \mathrm{~mm} \times 200 \mathrm{~mm} \times 600 \mathrm{~mm}, 200 \mathrm{~mm} \times$ $200 \mathrm{~mm} \times 1200 \mathrm{~mm}$ and $1500 \mathrm{~mm} \times 500 \mathrm{~mm} \times 300 \mathrm{~mm}$ for beam, column and foundation respectively. The vertical loading was applied to the beam at $530 \mathrm{~mm}$ distances from the column surface. Four sensors were used at specified positions at the beam and column surfaces. It was found that the increment of load intensity results in intensified acoustic emission signal strength.
\end{abstract}

Keywords RC Beam-Column Joint, Signal Strength, Acoustic Emission Technique, Damage Evaluation

\section{Introduction}

One of the critical reinforced concrete (RC) structural components is the beam-column joint that transfer moments from other elements connected to it. Simultaneously, the service life of an RC beam-column joint is limited due to depreciation, wear and tear, increased load, and changes in usage [1].

There are three broad categories of beam-column joints in RC structure where the exterior beam-column joint is highly influenced by external loadings. Furthermore, most of the RC beam-column joint majorly fails at the joint region due to development of shear crack. Hence, early detection of the crack occurrence should be implemented in order to maintain its integrity. Furthermore, inadequate reinforcement detailing in the $\mathrm{RC}$ structure will also affect the occurrence of damage [2 - 4]. Once damage occurs, the life span of the $\mathrm{RC}$ beam-column joint decreases, reducing the integrity of the $\mathrm{RC}$ beam-column joint.

Acoustic emission (AE) technique is one of the most extensively utilized non-destructive testing (NDT) methods in structural health monitoring. Many studies have thoroughly reported on structural health monitoring adopting the AE method [5-7]. This is attributed to the high sensitivity of the equipment to detect the early development of cracks and damages [8]. In fact, $\mathrm{AE}$ is a reliable method where a strong correlation between the AE activities and the damage progression were observed [9]. It is also potential in 
examining the level of damage in cementitious composites [10-11].

Thus, employing AE is vital to assess in regards to the structural integrity by identifying the occurrence of damages over time. Monitoring micro-cracks is often overlooked and undetectable by naked eyes where the AE can achieve the purpose [12]. Moreover, NDT approach is an alternative way to observe the damages without causing any damage to the structures. As a result, the goal of this research is to look into the crack propagation in the $\mathrm{RC}$ beam-column joint when it is monotonically loaded to failure on the beam using $\mathrm{AE}$ technique.

\section{Experimental Study}

\subsection{Sample Specification}

The RC beam-column joint sample was prepared and designed in accordance to Eurocode 2 with concrete grade $\mathrm{C} 40$. The concrete design was based on a ratio of 1:2:3 (cement: fine aggregate: coarse aggregate) with water to cement ratio of 0.46 . The RC beam-column joint was made from beam, column and foundation with the size of $300 \mathrm{~mm}$ × $200 \mathrm{~mm}$ × $600 \mathrm{~mm}, 200 \mathrm{~mm}$ x 200 $\mathrm{mm} \times 1200 \mathrm{~mm}$ and $1500 \mathrm{~mm} \times 500 \mathrm{~mm} \times 300 \mathrm{~mm}$, respectively. The beam was constructed at the middle of the column and the column was erected at the centre of the foundation.

There were four stages of the construction of the RC beam-column joint specimens. The first stage was the construction of the foundation. The foundation was reinforced with $16 \mathrm{~mm}$ diameter high yield steel bars with $80 \mathrm{~mm}$ centre to centre $(\mathrm{c} / \mathrm{c})$ followed by $100 \mathrm{~mm}$ centre to centre (c/c) spacings as the bottom layer and upper layer, respectively. The bars were placed at the bottom of the foundation with a concrete cover of $25 \mathrm{~mm}$.

The second stage was the construction of the column. Four $20 \mathrm{~mm}$ diameter high yield steel bars and $8 \mathrm{~mm}$ mild steel bar as link was designed for the column. The spacing between the links was $150 \mathrm{~mm}$ centre to centre. The third stage was the construction of the beam designed with two $12 \mathrm{~mm}$ diameter high yield steel bars procured to strengthen the tension and compression zone of the sample beams. The links was mild yield steel of $8 \mathrm{~mm}$ diameter with the spacing of $150 \mathrm{~mm}$ was used. Fourth stage was the assembling of formworks for the entire beam-column joint specimen. Conventional simple joint connection was used in the RC beam-column arrangement. Fig. 1 shows in detail the beam-column joint connection for the investigation.

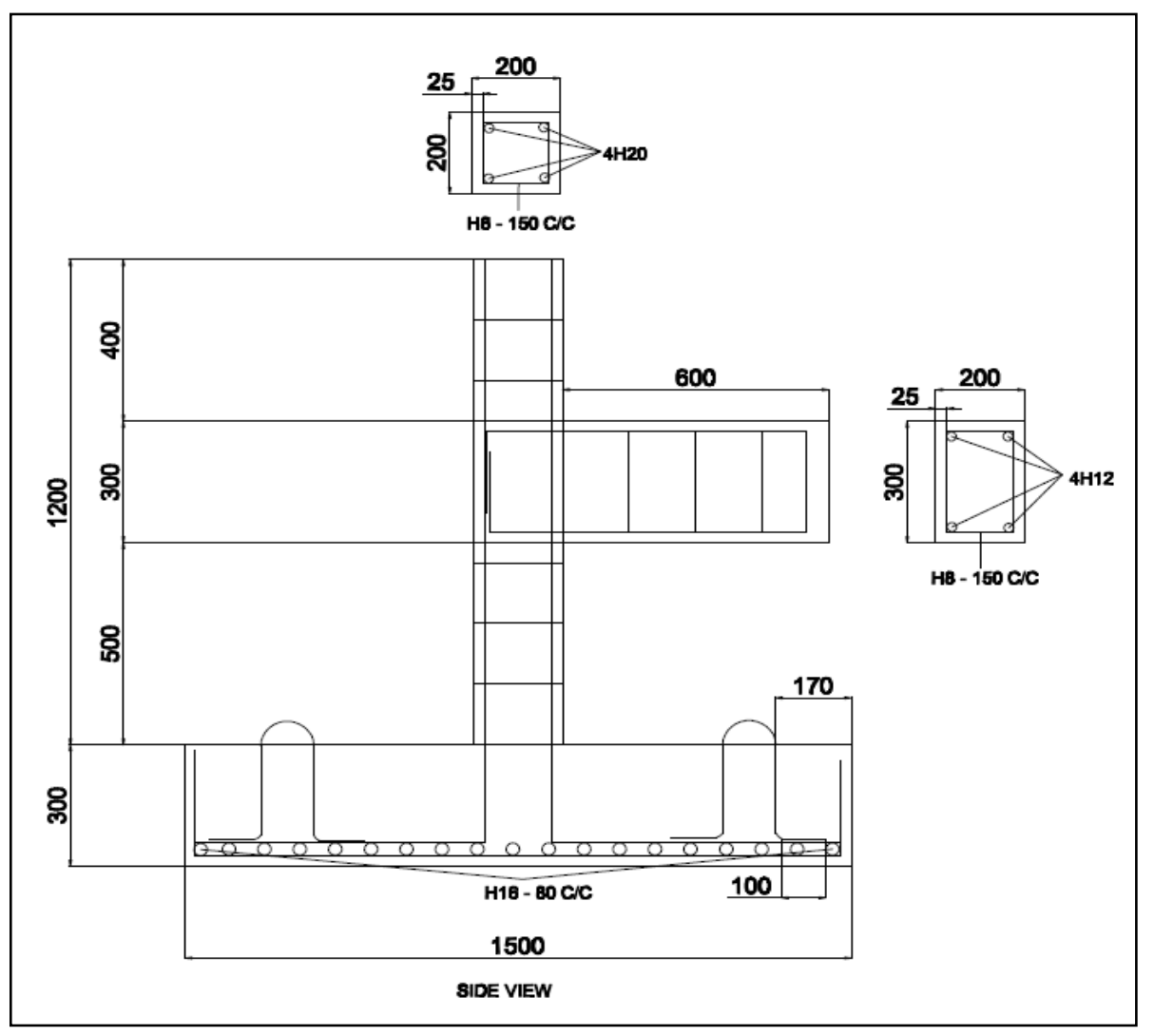

Figure 1. Details of the RC beam-column joint (all dimension measured in $\mathrm{mm}$ ) 


\subsection{Test Setup}

The RC beam-column joint was monotonically loaded to failure using Universal Testing Machine (UTM) with the capacity of $1000 \mathrm{kN}$. A constant load rate of 0.002 $\mathrm{mm} / \mathrm{s}$ was used throughout the testing. Fig. 2 illustrates the position of the applied load on the beam at a distance of $530 \mathrm{~mm}$ from the column surface. To avoid the joint transforming to bracket or corbel during the placing of load, the effective length was needed to be acquired of the load placement. According to Singh et al. [13], the optimum value to place the load was based on the shear span/ affective depth ratio $(\mathrm{a} / \mathrm{d})$ with the ratio a/d must be greater than 2 . In this study, the a/d was 2 which complied to the justification of Singh et al. [13].

\subsection{AE Instrumentation}

The AE type AMSYS-6 used in this study was provided by Vallen Systeme, Germany. The threshold was set to $40 \mathrm{~dB}$ with the $\mathrm{AE}$ wave velocity of 4000 $\mathrm{m} / \mathrm{s}$ in the AE hardware to remove the background noise (i.e. machineries appliances and ambient noise) [14]. Four sensors VS75 - V with frequency range between $20-100 \mathrm{kHz}$ were fixed on specified locations. Magnetic clamp with two legs of magnet was used to hold the sensor at the center of magnetic clamp. Then the legs were attached to two $2 \mathrm{~mm}$ steel plate that glued on the surface of RC beam-column joint specimen. High vacuum grease was applied between the sensor and the RC beam-column joint surface that act as a couplant. One sensor was attached at mid-height to one side of the beam surface with the distance of $30 \mathrm{~mm}$ from the tip of the beam edge and named as $\mathrm{CH} 5$. This channel was placed at below the beam to solve the difficulties such as the location of load applied and to simulate the real situation whereby presence of slab at the above part of the beam.

Three remaining sensors were attached at the center of the column width with the distance of $210 \mathrm{~mm}$ named as $\mathrm{CH} 6,550 \mathrm{~mm}$ named of $\mathrm{CH} 7$ and $950 \mathrm{~mm}$ named of $\mathrm{CH} 8$ from the top edge of the column. Fig. 3 and Fig. 4 show the schematic arrangement of the sensor on the RC beam-column joint and experimental set up for $\mathrm{AE}$ monitoring on $\mathrm{RC}$ beam-column joint. The sensors were connected using a cable to the pre-amplifier with the gain of $34 \mathrm{~dB}$. Then, the cable was connected to the ASIP-2 board. From the ASIP-2 board, it was connected to a computer for $\mathrm{AE}$ data acquisition. In this study, only $\mathrm{AE}$ signal strength collected from all channels was analysed to evaluate the crack behaviour of the sample.

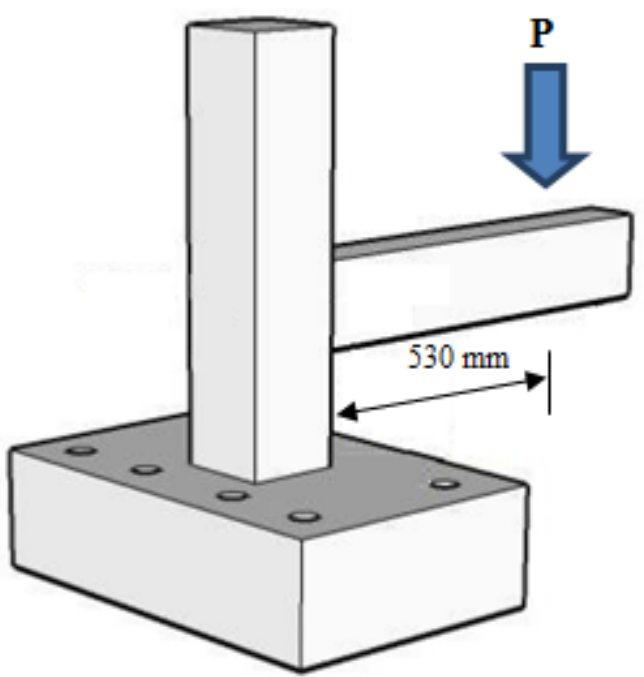

Figure 2. Schematic drawing of RC beam-column joint sub-assemblages

\subsection{Visual Observation}

Crack appeared during testing was retrieved by visual observation. The crack was mapped on a grid paper and redrawn on the RC beam-column joint surface when the load stopped. The crack which mapped on the grid paper was numbered as 1 and onwards. During the mapping process, the first crack that appeared on the surface of the specimen was identified. Torchlight was used to detect the crack initiation especially the occurrence of hairline crack [12].

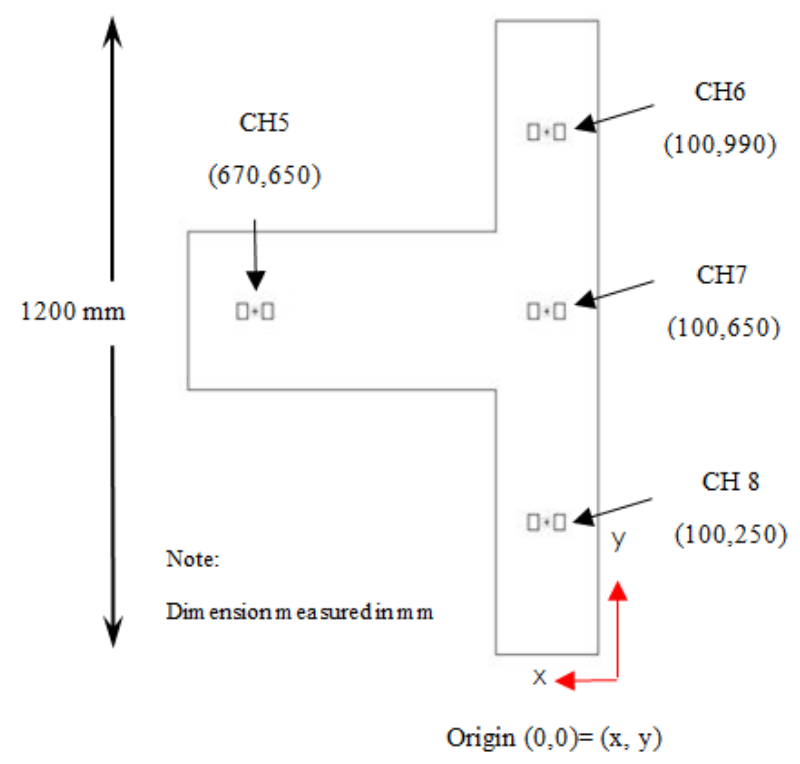

Figure 3. Schematic diagram location of the sensors 


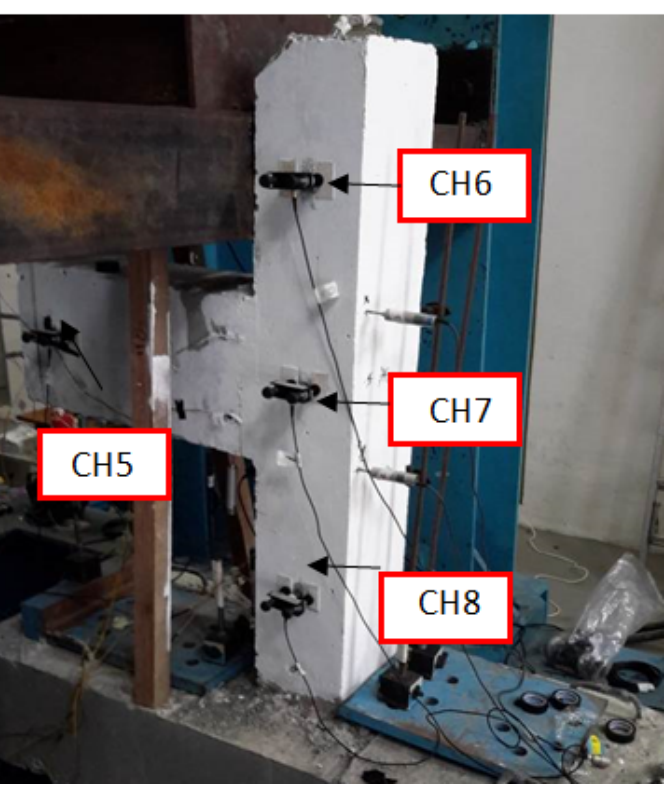

Figure 4. Experimental setup

\section{Results}

\subsection{Visual Observation of the RC Joint Sample}

The RC beam-column joint was tested using UTM machine and subjected to monotonic load. It can be remarked that the ultimate load of the RC beam-column joint was $46.16 \mathrm{kN}$. When the load reached $21.55 \mathrm{kN}$ at 168 seconds, the first crack was visible and marked as number 1, as shown in Fig. 5. The first crack was observed to appear vertically at the joint between the beam and the column. It indicates that when the load is approximately $47 \%$ of the ultimate load, the first crack occurred and can be visualised using naked eyes. Then, more cracks were developed at the joint and designated as 2 to 4 . The first diagonal crack designated as crack 5 occurred at the column as shown in Fig. 5. The crack was observed when the load reached $39.48 \mathrm{kN}$ or $86 \%$ of the ultimate load at $327 \mathrm{~s}$ which propagated approximately $45^{0}$ to the plane. The crack was then increased as the load increased. Similar crack pattern was also identified by Fadwa et al. [15].

At $355 \mathrm{~s}$, a single vertical crack occurred at the beam, designated as 6 . It was located at $270 \mathrm{~mm}$ from the joint, which occurred at centre between the column face and the point load. The crack was propagated from the top of the beam. Then, when the load reached $92 \%$ of the ultimate load or $42.53 \mathrm{kN}$, the crack was propagated from crack 6 to nearly mid-depth of the beam and designated as 8 . It was noted at time 404s. When the load increased, more cracks were developed. The cracks were seen to be more evident at the column and the joint of the RC beam-column joint.

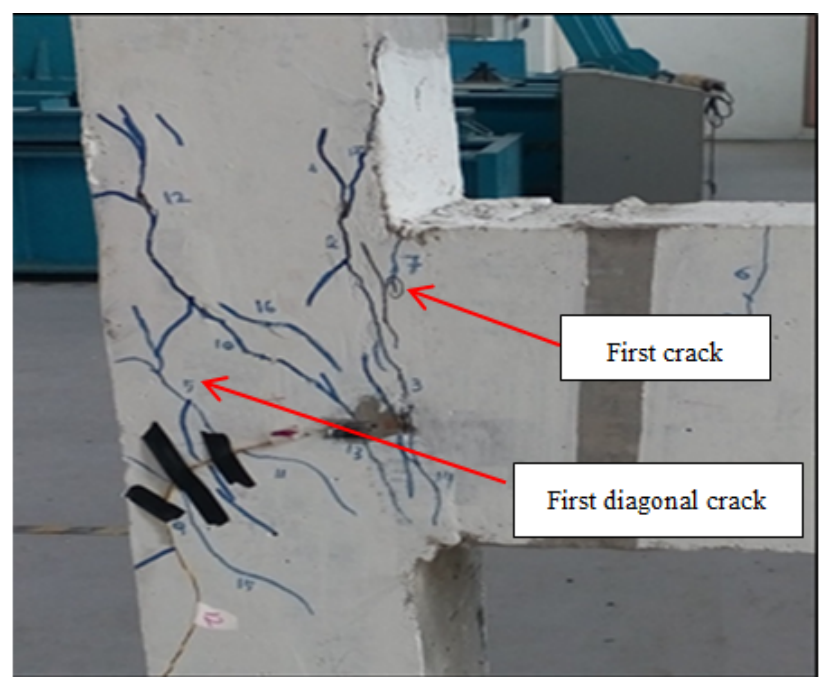

Figure 5. Crack pattern on the RC beam-column joint

\subsection{Signal Strength of RC Beam-Column Joint}

Fig. 6 depicts the correlation between signal strength, load and time when the beam of the RC beam-column joint was applied with a monotonic vertical point load. Meanwhile, Fig. 7 shows the relationship between signal strength and time corresponding to the crack modes of the joint sample. The signal strength was analysed from channels $5(\mathrm{CH} 5), 6(\mathrm{CH} 6), 7(\mathrm{CH} 7)$ and $8(\mathrm{CH} 8)$.

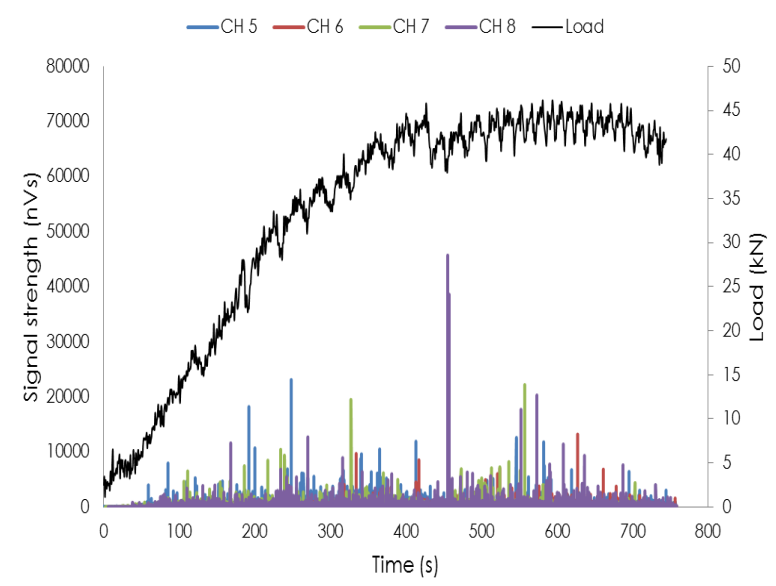

Figure 6. Relationship between signal strength, load and time

Generally, several crack modes were identified based on the relationship between signal strength and time corresponding to the crack modes that appeared on the RC beam-column joint. For instance, in Fig. 5 and Fig. 6, when load subjected to the beam of from $0 \mathrm{kN}$ to $12 \mathrm{kN}$, the crack nucleation that was not visible with naked eye was identified. Only one peak signal strength was noticed from time $0 \mathrm{~s}$ to $168 \mathrm{~s}$ (Fig. 7) captured by $\mathrm{CH} 5$ with the signal strength of $7950 \mathrm{nVs}$ at time $85 \mathrm{~s}$. The peak signal strength attained can be considered as the nucleation of 
crack which generated in the RC beam-column joint. According to Md Nor et al. [16] and Abdul Kudus et al. [17], the identification of crack existence corresponds to the peak observed from the signal strength. Moreover, Shield [18] stated that a major peak in AE signal preceded the crack. Hence, it is relevant to consider the signal strength of the $7950 \mathrm{nVs}$ as the nucleation of crack that might occur in the joint of the RC beam-column.

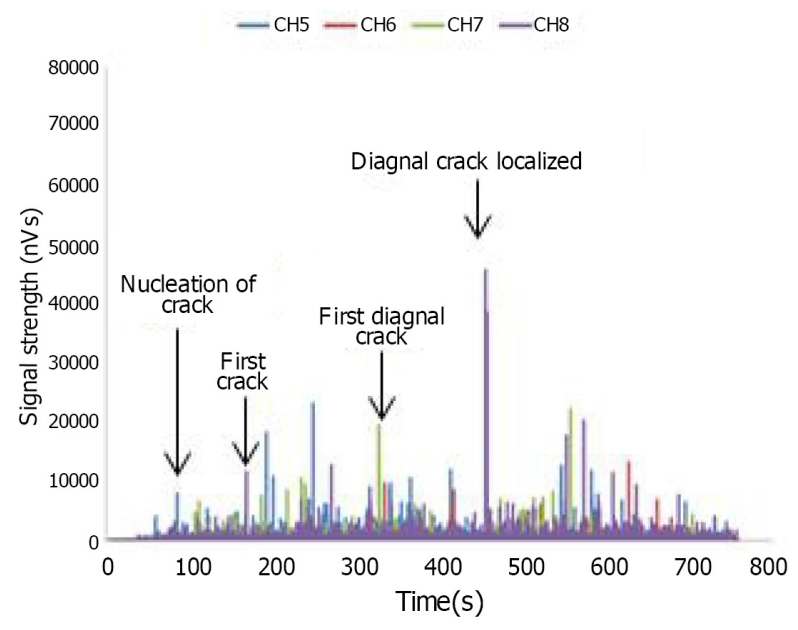

Figure 7. Relationship between signal strength and time for all channels

The occurrence of the first crack at the joint was visually observed when the load reached $21.55 \mathrm{kN}$ at time $168 \mathrm{~s}$. The signal strength was $11600 \mathrm{nVs}$ captured by CH8. It indicates that the signal strength increased as the crack occurred which generated high stress at that particular location. Md Nor et al. [16], Md Nor et al. [19], Wan Ahmad et al. [20], Bourchak et al. [21] and Mat Saliah et al. [22] confirmed that the presence of cracks in the structure is linked to high signal strength. Logically the crack happened at the joint will be captured at $\mathrm{CH} 7$ because it is very near to that occurrence of crack. But in this situation, CH5 was still captured the signal strength from first crack but the value was not so high compared that at $\mathrm{CH} 8$. This might be come from inhomogeneous condition of concrete inside the RC beam-column joint sample. For example, the segregation of aggregate inside the concrete that may slowdown the transient wave and reduce the signal strength of the $\mathrm{AE}$ data. But it was counter back by the nearest channel that captured the high signal strength. In this case $\mathrm{CH} 8$ captured the high value of signal strength for the first crack.

At time $248 \mathrm{~s}$, peak signal strength was noticed with the value $23100 \mathrm{nVs}$. The peak signal strength was collected by $\mathrm{CH} 5$ which is located close to the joint. The progression and propagation of the crack in the $\mathrm{RC}$ beam-column joint is the factor contributing to the high signal strength.

The first diagonal crack with an angle approximately $45^{\circ}$ to the plane of the column was identified at time $327 \mathrm{~s}$. The load of $39.48 \mathrm{kN}$ was induced high signal strength of $19500 \mathrm{nVs}$. The signal strength was collected from $\mathrm{CH} 7$.
When load reached $40.63 \mathrm{kN}$, a single vertical crack appeared on the beam with signal strength of $10500 \mathrm{nVs}$ at time $365 \mathrm{~s}$. The crack was initiated from the compression region of the beam. However, when the load reached $42.53 \mathrm{kN}$, the crack propagated to the tension part. The signal strength was increased to $11900 \mathrm{nVs}$ as the length of the crack increased.

The second diagonal crack at column was identified and produced highest signal strength of $45700 \mathrm{nVs}$ at time 455 $\mathrm{s}$. The load at $455 \mathrm{~s}$ was $41.58 \mathrm{kN}$. At this time, a loud noise can be heard that might be attributed to the progression of the diagonal crack in the $\mathrm{RC}$ beam-column joint. Then, it generated more diagonal cracks in the column and the cracks were localised.

Table 1 shows the summary of the AE signal strength corresponding to the time, load, crack type and channel $(\mathrm{CH})$. From the summary, it is found that the $\mathrm{CH} 8$ captured more peak signal strength than other channels. The nucleation of crack, first crack, flexural or vertical crack, and diagonal crack were identified as the four main outcomes of crack development. From the four crack modes, the diagonal cracks were dominant. Most of the diagonal cracks were captured by $\mathrm{CH} 8$, because the $\mathrm{CH} 8$ or sensor 8 is located at the column hence recorded more signals than other channels.

Table 1. The summary of the AE signal strength, time, load, crack types and channel

\begin{tabular}{|c|c|c|c|c|}
\hline $\begin{array}{c}\text { Time } \\
(\mathbf{s})\end{array}$ & $\begin{array}{c}\text { Load } \\
(\mathbf{k N})\end{array}$ & $\mathbf{C H}$ & $\begin{array}{c}\text { Signal } \\
\text { Strength } \\
(\mathbf{n V s})\end{array}$ & Crack modes \\
\hline 85 & 12 & 5 & 7950 & Nucleation of crack \\
\hline 168 & 21.55 & 8 & 11600 & First crack \\
\hline 202 & 31.85 & 7 & 8470 & Flexural vertical \\
\hline 224 & 29.37 & 7 & 10400 & Flexural vertical \\
\hline 229 & 30.90 & 7 & 9380 & Flexural vertical \\
\hline 327 & 39.48 & 7 & 19500 & Diagonal crack \\
\hline 365 & 40.63 & 5 & 10500 & Flexural vertical \\
\hline 377 & 41.39 & 7 & 4960 & Flexural vertical \\
\hline 403 & 42.53 & 5 & 11900 & Flexural vertical \\
\hline 446 & 39.86 & 8 & 38600 & Diagonal crack \\
\hline 455 & 41.58 & 8 & 45700 & Diagonal crack \\
\hline
\end{tabular}

\subsection{Relationship between Cumulative Signal Strength and Time for All Channels}

Fig. 8 shows the cumulative signal strength for all channels with respect to time. From the graph, $\mathrm{CH} 8$ produced highest cumulative signal strength compared to other channels, because $\mathrm{CH} 8$ is located at mid-width of the column and $250 \mathrm{~mm}$ from the foundation. This channel was not near to the concentration of the crack occurrence in the joint area of the sample. It depends on the material of the concrete itself such as segregation of the material that can slowdown the wave and decrease the 
signal strength. But can support the nearest channel as long the channel location $1 \mathrm{~m}$ from other channel. Hence, it would have captured the highest signal strength that released by the cracks. The peak cumulative signal strength for $\mathrm{CH} 8$ is $3.99 \times 10^{6} \mathrm{nVs}$.

The second highest cumulative signal strength was captured by $\mathrm{CH} 5$. The cumulative signal strength value is $3.08 \times 10^{6} \mathrm{nVs}$. The CH5 was located at one side of the beam, close to the point load. When load is applied to the beam, the $\mathrm{CH} 5$ captured signal from the crack activity in the beam. $\mathrm{CH} 7$ produced the third graph of cumulative signal strength with the value of $2.40 \times 10^{6} \mathrm{nVs}$. The $\mathrm{CH} 7$ was located close to the joint of the RC beam-column. Meanwhile, the $\mathrm{CH} 6$ was produced little cumulative signal strength of $1.71 \times 10^{6} \mathrm{nVs}$. The $\mathrm{CH} 6$ was located at $650 \mathrm{~mm}$ from the foundation.

From these values of cumulative signal strength, the location of the channels is important to capture signal released from the crack [12,19-21]. At the same time, the motion of the wave induced by the crack is also to be taken into consideration.

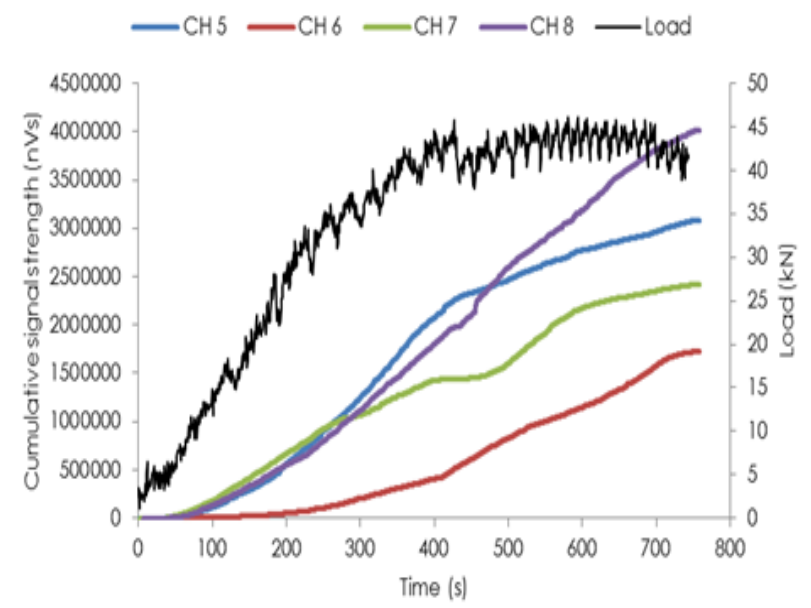

Figure 8. Cumulative signal strength and load with respect to time for all channels

\section{Conclusions}

$\mathrm{AE}$ is a practical approach in monitoring the fracture mechanisms of RC structural elements explicitly. Higher monotonic load intensity increases the $\mathrm{AE}$ activities. It can be observed that most of the crack in the RC beam-column joint was concentrated at the central area of the joint sample. Four types of cracks were identified with reference to the signal strength. The cracks progressed from crack nucleation to first crack, first diagonal crack, and localised diagonal crack. Cracks were also discovered to evolve in three distinctive stages. It began with flexural cracks in the early stages and progressed to mixed mode cracks with broader flexural crack coverage in the second stage. The final stage reveals that diagonal cracks appeared massively before the RC beam-column joint failed.

\section{Acknowledgments}

The authors would like to express their gratitude to the Ministry of Education (MOE) for funding the research works under Grant No. RAGS/1/2014/TK02/UITM/19. Acknowledgement is also conveyed to Universiti Teknologi MARA, Cawangan Pulau Pinang for offering the facilities to complete the laboratory works.

\section{REFERENCES}

[1] H.D. Yun, W.C. Choi, S.Y. Seo. Acoustic emission activities and damage evaluation of reinforced concrete beams strengthened with CFRP sheets, NDT\&E International, Vol. 43, 615-628, 2010.

[2] P. Muthupriya, S.C. Boobalan, B.G. Visnuram. Behaviour of fibre-reinforced high-performance concrete in exterior beam-column joint. International Journal of Advanced Structural Engineering, Vol. 6, No. $3,1-7,2014$

[3] B. Singh, S. Dhiman. The Experimental Behavior of the CFST Column and Beam Externally Bonded by CFRP Strips. Civil Engineering and Architecture, Vol. 9, No. 3, 656-669, 2021. DOI: 10.13189/cea.2021.090309

[4] S. Shamim, S. Ahmad, R. Ahmad Khan. Blast Vulnerability of Multi-Storey Masonry Infill Reinforced Concrete Frames. Civil Engineering and Architecture, Vol.9, No. 3, 853 - 868, 2021. DOI: $10.13189 /$ cea.2021.090327

[5] N. Md Nor. An overview on fatigue damage assessment of reinforced concrete structures with the aid of acoustic emission technique, Construction \& Building Materials, Vol. 112, 424-439, 2016.

[6] N. Md Nor. Structural Health monitoring through acoustic emission: Eco-efficient repair and rehabilitation of concrete infrastructures, edited by F. Pacheco-Torgal, Robert E. Melchers, Xianming Shi, Nele De Belie, Kim Van Tittelboom, Andres Saez, Woodhead Publishing and Elsevier Ltd, 2018.

[7] A. Behnia, H.K. Chai, T. Shiotani. Advanced structural health monitoring of concrete structures with the aid of acoustic emission, Construction and Building Materials, Vol. 65, $282-302,2014$.

[8] M. Kaple. Analysis of Acoustic Emission Data for Accurate Damage Assessment for Structural Health Monitoring, 2012.

[9] T. Nguyen-tat, N. Ranaivomanana, J. Balayssac. Characterizaiton of Damage in Concrete Beams under Bending with Acoustic Emission Technique (AET), Construction Building and Material, Vol. 187, 487 - 500, 2018.

[10] X. Hernan, F. Paula, N. Nicolas, G. Martin, C. Antonio, M. Enzo. Acoustic Emission behavior of thermally damaged 
Self-Compacting High Strength Fiber Reinforced Concrete, Construction and Building Materials, Vol. 187, 519-530, 2018.

[11] S. Tayfur, E. Ercan, K. Ohno, N. Alver. Acoustic Emission for Monitoring of Strengthened RC Beam-Column Joints. $5^{\text {th }}$ International Conference on Road and Rail Infrastructure, 95 - 101, 2018.

[12] X. Zhang, B. Li. Damage characteristics and assessment of corroded RC beam-column joint under cyclic loading based on acoustic emission monitoring, Engineering Structures, Vol. 205, 2020.

[13] V. Singh, P.P Bansal, M. Kumar, S.K. Kaushik. Experimental studies on strength and ductility of CFRP jacketed reinforced concrete beam-column joints. Construction and Building Materials, Vol. 55, 194-201, 2014.

[14] N. Md Nor, A. Ibrahim, N. Muhamad Bunnori, H. Mohd Saman. Acoustic emission signal for fatigue crack classification on reinforced concrete beam. Construction and Building Material, Vol. 49, 583-590, 2013.

[15] I. Fadwa, T.A. Ali, E. Nazih, M. Sara. Reinforced concrete wide and conventional beam-column connections subjected to lateral load. Engineering Structure, Vol. 76, 34-48, 2014.

[16] N. Md Nor, A. Ibrahim, N. Muhamad Bunnori, H. Mohd Saman, S.N. Mat Saliah, S. Shahidan. Diagnostic of fatigue damage severity on reinforced concrete beam using acoustic emission technique, Engineering Failure Analysis, Vol. 41, 1-9, 2014
[17] N. Md Nor, S. Abdullah, S.N. Mat Saliah. On the need to determine the acoustic emission trend for reinforced concrete beam fatigue damage, International Journal of Fatigue, 2021.

[18] C.K. Shield. Comparison of acoustic emission activity in reinforced and prestressed concrete beams under bending, Construction and Building Material, Vol. 11, No. 3, $189-$ 194, 1997.

[19] N. Md Nor, S.N. Mat Saliah. Acoustic emission signal strength for damage evaluation of reinforced concrete beam, ARPN Journal of Engineering and Applied Sciences, Vol. 11, No. 4, $2622-2626,2016$

[20] W.N.A. Wan Ahmad, N. Md Nor. A study on damage assessment of RC beam wrapped with carbon fibre sheets using parameters of acoustic emission signal ARPN Journal of Engineering and Applied Sciences, Vol. 11, No. 4, 53915396, 2016.

[21] M. Bourchak, I.R. Farrow, I.P. Bond, C.W. Rowland, F. Menan. Acoustic emission energu as a fatigue damage parameter for CFRP laminates, International Journal of Fatigue, Vol. 29, 457-470, 2007.

[22] M.S. Soffian Noor, N. Md Nor, N. Abd Rahman, S. Abdullah, M.S. Tahir. Evaluation of severely damaged reinforced concrete beam repaired with epoxy injection using acoustic emission technique, Theoretical and Applied Fracture Mechanics, Vol. 112, 2021. 